\title{
FIXED POINT THEOREMS USING IMPLICIT RELATION IN PARTIAL METRIC SPACES
}

\author{
Gurucharan Singh Saluja
}

(C) by University of Niš, Serbia | Creative Commons Licence: CC BY-NC-ND Abstract. This paper aims to establish some $\mathrm{C}$ using implicit relation in the framework of complete partial metric spaces, and also, to obtain other well-known results as corollaries to the result. The results presented in this paper extend and generalize several results from the existing literature to the setting of more general metric spaces and contraction conditions.

Keywords: contraction conditions; contraction conditions; complete partial metric spaces.

\section{Introduction and Preliminaries}

Let $(X, d)$ be a metric space and let $S: X \rightarrow X$ be a self-mapping.

(i) A point $x \in X$ is called a fixed point of $S$ if $x=S x$.

(ii) $S$ is called contraction if there exists a fixed constant $0 \leq r<1$ such that

$$
d(S(x), S(y)) \leq r d(x, y)
$$

for all $x, y \in X$. If $X$ is complete, then every contraction has a unique fixed point and that point can be obtained as a limit of repeated iteration of the mapping at any point of $X$ (the Banach contraction principle). Obviously, every contraction is a continuous function. The Banach contraction mappings principle is the opening and vital result in the direction of fixed point theory. Subsequently, several authors have devoted their concentration to expanding and improving this theory (see, e.g., $[6,7,15,16,22,23,24])$.

Matthews $([12,13])$ launched the notion of partial metric space and proved equivalent result of Banach's theorem in such spaces. Afterwards, a multitude of results was obtained in these spaces (see, e.g., [2, 3, 9, 10, 15, 18, 20, 21]). Also, the concept of PMS provides to study denotational semantics of dataflow networks $[12,13,17,19]$.

Received October 26, 2019; accepted February 26, 2020

2010 Mathematics Subject Classification. 47H10, 54H25. 
Matthews [12] introduced the notion of partial metric spaces as follows:

Definition 1.1. ([12]) Let $X$ be a nonempty set and let $p: X \times X \rightarrow \mathbb{R}^{+}$be a function satisfy

(p1) $x=y \Leftrightarrow p(x, x)=p(x, y)=p(y, y)$,

(p2) $p(x, x) \leq p(x, y)$,

(p3) $p(x, y)=p(y, x)$

(p4) $p(x, y) \leq p(x, z)+p(z, y)-p(z, z)$,

for all $x, y, z \in X$. Then $p$ is called partial metric on $X$ and the pair $(X, p)$ is called partial metric space.

It is clear that if $p(x, y)=0$, then from $(p 1)$ and $(p 2)$ we obtain $x=y$. But if $x=y, p(x, y)$ may not be zero. Various applications of this space has been extensively investigated by many authors (see [11], [18] for details).

Example 1.1. ([4]) Let $X=\mathbb{R}^{+}$and $p: X \times X \rightarrow \mathbb{R}^{+}$given by $p(x, y)=\max \{x, y\}$ for all $x, y \in \mathbb{R}^{+}$. Then $\left(\mathbb{R}^{+}, p\right)$ is a partial metric space.

Example 1.2. ([4]) Let $X=\{[a, b]: a, b \in \mathbb{R}, a \leq b\}$. Then $p([a, b],[c, d])=\max \{b, d\}-$ $\min \{a, c\}$ defines a partial metric $p$ on $X$.

Remark 1.1. ([8]) Let $(X, p)$ be a partial metric space.

(a1) The function $d_{M}: X \times X \rightarrow \mathbb{R}^{+}$defined as $d_{M}(x, y)=2 p(x, y)-p(x, x)-p(y, y)$ is a (usual) metric on $X$ and $\left(X, d_{M}\right)$ is a (usual) metric space.

(a2) The function $d_{S}: X \times X \rightarrow \mathbb{R}^{+}$defined as $d_{S}(x, y)=\max \{p(x, y)-p(x, x), p(x, y)-$ $p(y, y)\}$ is a (usual) metric on $X$ and $\left(X, d_{S}\right)$ is a (usual) metric space.

Note also that each partial metric $p$ on $X$ generates a $T_{0}$ topology $\tau_{p}$ on $X$, whose base is a family of open $p$-balls $\left\{B_{p}(x, \varepsilon): x \in X, \varepsilon>0\right\}$ where $B_{p}(x, \varepsilon)=$ $\{y \in X: p(x, y) \leq p(x, x)+\varepsilon\}$ for all $x \in X$ and $\varepsilon>0$.

On a partial metric space the notions of convergence, the Cauchy sequence, completeness and continuity are defined as follows [12].

Definition 1.2. ([12]) Let $(X, p)$ be a partial metric space. Then

(b1) a sequence $\left\{x_{n}\right\}$ in $(X, p)$ is said to be convergent to a point $x \in X$ if and only if $p(x, x)=\lim _{n \rightarrow \infty} p\left(x_{n}, x\right)$,

(b2) a sequence $\left\{x_{n}\right\}$ is called a Cauchy sequence if $\lim _{m, n \rightarrow \infty} p\left(x_{m}, x_{n}\right)$ exists and finite, 
(b3) $(X, p)$ is said to be complete if every Cauchy sequence $\left\{x_{n}\right\}$ in $X$ converges to a point $x \in X$ with respect to $\tau_{p}$. Furthermore,

$$
\lim _{m, n \rightarrow \infty} p\left(x_{m}, x_{n}\right)=\lim _{n \rightarrow \infty} p\left(x_{n}, x\right)=p(x, x) .
$$

(b4) A mapping $F: X \rightarrow X$ is said to be continuous at $x_{0} \in X$ if for every $\varepsilon>0$, there exists $\delta>0$ such that $F\left(B_{p}\left(x_{0}, \delta\right)\right) \subset B_{p}\left(F\left(x_{0}\right), \varepsilon\right)$.

Definition 1.3. ([14]) Let $(X, p)$ be a partial metric space. Then

(c1) a sequence $\left\{x_{n}\right\}$ in $(X, p)$ is called 0-Cauchy if $\lim _{m, n \rightarrow \infty} p\left(x_{m}, x_{n}\right)=0$,

$(c 2)(X, p)$ is said to be 0 -complete if every 0-Cauchy sequence $\left\{x_{n}\right\}$ in $X$ converges to a point $x \in X$, such that $p(x, x)=0$.

Lemma 1.1. ([12, 13]) Let $(X, p)$ be a partial metric space. Then

(d1) a sequence $\left\{x_{n}\right\}$ in $(X, p)$ is a Cauchy sequence if and only if it is a Cauchy sequence in the metric space $\left(X, d_{M}\right)$,

(d2) $(X, p)$ is complete if and only if the metric space $\left(X, d_{M}\right)$ is complete,

(d3) a subset $E$ of a partial metric space $(X, p)$ is closed if a sequence $\left\{x_{n}\right\}$ in $E$ such that $\left\{x_{n}\right\}$ converges to some $x \in X$, then $x \in E$.

Lemma 1.2. ([1]) Assume that $x_{n} \rightarrow z$ as $n \rightarrow \infty$ in a partial metric space $(X, p)$ such that $p(z, z)=0$. Then $\lim _{n \rightarrow \infty} p\left(x_{n}, y\right)=p(z, y)$ for every $y \in X$.

Now, an implicit relation has been introduced to investigate some fixed point and common fixed point theorems in partial metric spaces.

Definition 1.4. (Implicit Relation) Let $\Psi$ be the family of all real valued continuous functions $\psi: \mathbb{R}_{+}^{4} \rightarrow \mathbb{R}_{+}$, for four variables. For some $h \in[0,1)$, we consider the following conditions.

(r1) For $x, y \in \mathbb{R}_{+}$, if $y \leq \psi\left(x, x, y, \frac{x+y}{2}\right)$, then $y \leq h x$.

$(r 2)$ For $x \in \mathbb{R}_{+}$, if $y \leq \psi\left(0,0, y, \frac{y}{2}\right)$, then $y=0$.

(r3) For $x \in \mathbb{R}_{+}$, if $y \leq \psi(y, 0,0, y)$, then $y=0$, since $h \in[0,1)$.

The purpose of this paper is to establish some fixed point and common fixed point theorems in the setting of partial metric spaces using implicit relation. The results of findings extend and generalize several results from the existing literature. 


\subsection{Main Results}

In this section, some fixed point and common fixed point theorems shall be proved using implicit relation in the framework of partial metric spaces.

Theorem 1.1. Let $(X, p)$ be a complete partial metric space and let $T: X \rightarrow X$ be a mapping satisfying the inequality

$$
\begin{aligned}
& p(T x, T y) \leq \psi\{p(x, y), p(x, T x), p(y, T y), \\
&\left.\frac{1}{2}[p(x, T y)+p(y, T x)]\right\},
\end{aligned}
$$

for all $x, y \in X$ and some $\psi \in \Psi$. Then we have

(a) If $\psi$ satisfies the conditions ( $r 1)$ and $(r 2)$, then $T$ has a fixed point. Moreover, for any $x_{0} \in X$ and the fixed point $z$, we have

$$
p\left(T x_{n}, z\right) \leq\left(\frac{h^{n}}{1-h}\right) p\left(x_{0}, T x_{0}\right) .
$$

(b) If $\psi$ satisfies the condition ( $r 3$ ), then $T$ admits a unique fixed point.

Proof. (a) For each $x_{0} \in X$ and $n \in \mathbb{N}$, put $x_{n+1}=T x_{n}$. It follows from (1.2) and (p4) that

$$
\begin{aligned}
p\left(x_{n}, x_{n+1}\right) & =p\left(T x_{n-1}, T x_{n}\right) \\
& \leq \psi\left\{p\left(x_{n-1}, x_{n}\right), p\left(x_{n-1}, T x_{n-1}\right), p\left(x_{n}, T x_{n}\right),\right. \\
\left.\frac{1}{2}\left[p\left(x_{n-1}, T x_{n}\right)+p\left(x_{n}, T x_{n-1}\right)\right]\right\} & \left.\frac{1}{2}\left[p\left(x_{n-1}, x_{n+1}\right)+p\left(x_{n}, x_{n}\right)\right]\right\} \\
& \leq \psi\left\{p\left(x_{n-1}, x_{n}\right), p\left(x_{n-1}, x_{n}\right), p\left(x_{n}, x_{n+1}\right),\right. \\
& \leq \psi\left\{p\left(x_{n-1}, x_{n}\right), p\left(x_{n-1}, x_{n}\right), p\left(x_{n}, x_{n+1}\right),\right. \\
\left.\frac{1}{2}\left[p\left(x_{n-1}, x_{n}\right)+p\left(x_{n}, x_{n+1}\right)-p\left(x_{n}, x_{n}\right)\right]\right\} & \left.\frac{1}{2}\left[p\left(x_{n-1}, x_{n}\right)+p\left(x_{n}, x_{n+1}\right)\right]\right\}
\end{aligned}
$$

Since $\psi$ satisfies the condition $(r 1)$, there exists $h \in[0,1)$ such that

$$
p\left(x_{n}, x_{n+1}\right) \leq h p\left(x_{n-1}, x_{n}\right) \leq h^{n} p\left(x_{0}, x_{1}\right) .
$$

Set $A_{n}=p\left(x_{n}, x_{n+1}\right)$ and $A_{n-1}=p\left(x_{n-1}, x_{n}\right)$, then from (1.4), we obtain

$$
A_{n} \leq h A_{n-1} \leq h^{2} A_{n-2} \leq \cdots \leq h^{n} A_{0} .
$$


Now, we show that $\left\{x_{n}\right\}$ is a Cauchy sequence in $X$. Let $m, n>0$ with $m>n$, then by using $(p 4)$ and equation (1.4), we have

$$
\begin{aligned}
p\left(x_{n}, x_{m}\right) \leq & p\left(x_{n}, x_{n+1}\right)+p\left(x_{n+1}, x_{n+2}\right)+\cdots+p\left(x_{n+m-1}, x_{m}\right) \\
& -p\left(x_{n+1}, x_{n+1}\right)-p\left(x_{n+2}, x_{n+2}\right)-\cdots-p\left(x_{n+m-1}, x_{n+m-1}\right) \\
\leq & h^{n} p\left(x_{0}, x_{1}\right)+h^{n+1} p\left(x_{0}, x_{1}\right)+\cdots+h^{n+m-1} p\left(x_{0}, x_{1}\right) \\
= & h^{n}\left[p\left(x_{0}, x_{1}\right)+h p\left(x_{0}, x_{1}\right)+\cdots+h^{m-1} p\left(x_{0}, x_{1}\right)\right] \\
= & h^{n}\left[1+h+\cdots+h^{m-1}\right] A_{0} \\
\leq & h^{n}\left(\frac{1-h^{m-1}}{1-h}\right) A_{0} .
\end{aligned}
$$

Taking $n, m \rightarrow \infty$ in the above inequality, we get $p\left(x_{n}, x_{m}\right) \rightarrow 0$ since $0<h<1$, hence $\left\{x_{n}\right\}$ is a Cauchy sequence in $X$. Thus by Lemma 1.1 this sequence will also Cauchy in $\left(X, d_{M}\right)$. In addition, since $(X, p)$ is complete, $\left(X, d_{M}\right)$ is also complete. Thus there exists $z \in X$ such that $x_{n} \rightarrow z$ as $n \rightarrow \infty$. Moreover by Lemma 1.1,

$$
p(z, z)=\lim _{n \rightarrow \infty} p\left(z, x_{n}\right)=\lim _{n, m \rightarrow \infty} p\left(x_{n}, x_{m}\right)=0,
$$

implies

$$
\lim _{n \rightarrow \infty} d_{M}\left(z, x_{n}\right)=0 .
$$

Moreover, taking the limit as $m \rightarrow \infty$ we get

$$
p\left(x_{n}, z\right) \leq\left(\frac{h^{n}}{1-h}\right) p\left(x_{1}, x_{0}\right) .
$$

It implies that

$$
p\left(T x_{n}, z\right) \leq\left(\frac{h^{n}}{1-h}\right) p\left(x_{0}, T x_{0}\right) .
$$

Now, we show that $z$ is a fixed point of $T$. Notice that due to (1.5), we have $p(z, z)=0$. By using inequality (1.2), we get

$$
\begin{aligned}
& p\left(x_{n+1}, T z\right)=p\left(T x_{n}, T z\right) \\
& \leq \psi\left\{p\left(x_{n}, z\right), p\left(x_{n}, T x_{n}\right), p(z, T z)\right. \\
&\left.\frac{1}{2}\left[p\left(x_{n}, T z\right)+p\left(z, T x_{n}\right)\right]\right\} \\
&=\psi\left\{p\left(x_{n}, z\right), p\left(x_{n}, x_{n+1}\right), p(z, T z)\right. \\
&\left.\frac{1}{2}\left[p\left(x_{n}, T z\right)+p\left(z, x_{n+1}\right)\right]\right\} .
\end{aligned}
$$

Note that $\psi \in \Psi$, then taking the limit as $n \rightarrow \infty$ and using (1.5) and Lemma 1.2, we get

$$
p(z, T z) \leq \psi\left\{0,0, p(z, T z), \frac{1}{2} p(z, T z)\right\}
$$


Since $\psi$ satisfies the condition $(r 2)$, then $p(z, T z) \leq h .0=0$. This shows that $z=T z$. Thus $z$ is a fixed point of $T$.

(b) Let $z_{1}, z_{2}$ be fixed points of $T$ with $z_{1} \neq z_{2}$. We shall prove that $z_{1}=z_{2}$. It follows from equation (1.2) and (1.5) that

$$
\begin{aligned}
& p\left(z_{1}, z_{2}\right)=p\left(T z_{1}, T z_{2}\right) \\
& \leq \psi\left\{p\left(z_{1}, z_{2}\right), p\left(z_{1}, T z_{1}\right), p\left(z_{2}, T z_{2}\right)\right. \\
&\left.\frac{1}{2}\left[p\left(z_{1}, T z_{2}\right)+p\left(z_{2}, T z_{1}\right)\right]\right\} \\
&=\psi\left\{p\left(z_{1}, z_{2}\right), p\left(z_{1}, z_{1}\right), p\left(z_{2}, z_{2}\right),\right. \\
&\left.\frac{1}{2}\left[p\left(z_{1}, z_{2}\right)+p\left(z_{2}, z_{1}\right)\right]\right\} \\
&=\psi\left\{p\left(z_{1}, z_{2}\right), 0,0, p\left(z_{1}, z_{2}\right)\right\} .
\end{aligned}
$$

Since $\psi$ satisfies the condition $(r 3)$, then we get

$$
\begin{aligned}
p\left(z_{1}, z_{2}\right) & \leq h p\left(z_{1}, z_{2}\right) \\
& \Rightarrow p\left(z_{1}, z_{2}\right)=0, \text { since } 0<h<1 .
\end{aligned}
$$

This shows that $z_{1}=z_{2}$. Thus, the fixed point of $T$ is unique. This completes the proof.

Theorem 1.2. Let $T_{1}$ and $T_{2}$ be two self-maps on a complete partial metric space $(X, p)$ and

$$
\begin{array}{r}
p\left(T_{1} x, T_{2} y\right) \leq \psi\left\{p(x, y), p\left(x, T_{1} x\right), p\left(y, T_{2} y\right)\right. \\
\left.\frac{p\left(x, T_{2} y\right)+p\left(y, T_{1} x\right)}{2}\right\}
\end{array}
$$

for all $x, y \in X$ and some $\psi \in \Psi$. Then $T_{1}$ and $T_{2}$ have a unique common fixed point in $X$.

Proof. For each $x_{0} \in X$. Put $x_{2 n+1}=T_{1} x_{2 n}$ and $x_{2 n+2}=T_{2} x_{2 n+1}$ for $n=$ 
$0,1,2, \ldots$ It follows from $(1.7),(p 4)$ and Lemma 1.1 that

$$
\begin{aligned}
& p\left(x_{2 n+1}, x_{2 n}\right)= p\left(T_{1} x_{2 n}, T_{2} x_{2 n-1}\right) \\
& \leq \psi\left\{p\left(x_{2 n}, x_{2 n-1}\right), p\left(x_{2 n}, T_{1} x_{2 n}\right), p\left(x_{2 n-1}, T_{2} x_{2 n-1}\right),\right. \\
&\left.\frac{p\left(x_{2 n}, T_{2} x_{2 n-1}\right)+p\left(x_{2 n-1}, T_{1} x_{2 n}\right)}{2}\right\}\left.\frac{p\left(x_{2 n}, x_{2 n}\right)+p\left(x_{2 n-1}, x_{2 n+1}\right)}{2}\right\} \\
&= \psi\left\{p\left(x_{2 n}, x_{2 n-1}\right), p\left(x_{2 n}, x_{2 n+1}\right), p\left(x_{2 n-1}, x_{2 n}\right),\right. \\
& \leq \psi\left\{p\left(x_{2 n}, x_{2 n-1}\right), p\left(x_{2 n}, x_{2 n+1}\right), p\left(x_{2 n-1}, x_{2 n}\right),\right. \\
&\left.\frac{p\left(x_{2 n-1}, x_{2 n}\right)+p\left(x_{2 n}, x_{2 n+1}\right)-p\left(x_{2 n}, x_{2 n}\right)}{2}\right\} \\
& \leq
\end{aligned}
$$

Since $\psi$ satisfies the condition $(r 1)$, there exists $h \in[0,1)$ such that

$$
p\left(x_{2 n+1}, x_{2 n}\right) \leq h p\left(x_{2 n}, x_{2 n-1}\right) \leq h^{2 n} p\left(x_{1}, x_{0}\right) .
$$

Now, we show that $\left\{x_{n}\right\}$ is a Cauchy sequence in $X$. Let $m, n>0$ with $m>n$, then by using $(p 4)$ and equation (1.9), we have

$$
\begin{aligned}
p\left(x_{n}, x_{m}\right) \leq & p\left(x_{n}, x_{n+1}\right)+p\left(x_{n+1}, x_{n+2}\right)+\cdots+p\left(x_{n+m-1}, x_{m}\right) \\
& -p\left(x_{n+1}, x_{n+1}\right)-p\left(x_{n+2}, x_{n+2}\right)-\cdots-p\left(x_{n+m-1}, x_{n+m-1}\right) \\
\leq & h^{n} p\left(x_{0}, x_{1}\right)+h^{n+1} p\left(x_{0}, x_{1}\right)+\cdots+h^{n+m-1} p\left(x_{0}, x_{1}\right) \\
= & h^{n}\left[p\left(x_{0}, x_{1}\right)+h p\left(x_{0}, x_{1}\right)+\cdots+h^{m-1} p\left(x_{0}, x_{1}\right)\right] \\
= & h^{n}\left[1+h+\cdots+h^{m-1}\right] p\left(x_{0}, x_{1}\right) \\
\leq & h^{n}\left(\frac{1-h^{m-1}}{1-h}\right) p\left(x_{0}, x_{1}\right) .
\end{aligned}
$$

Taking $n, m \rightarrow \infty$ in the above inequality, we get $p\left(x_{n}, x_{m}\right) \rightarrow 0$ since $0<h<1$, hence $\left\{x_{n}\right\}$ is a Cauchy sequence in $X$. Thus, by Lemma 1.1 this sequence will also Cauchy in $\left(X, d_{M}\right)$. In addition, since $(X, p)$ is complete, $\left(X, d_{M}\right)$ is also complete. Thus there exists $u \in X$ such that $x_{n} \rightarrow u$ as $n \rightarrow \infty$. Moreover by Lemma 1.1,

$$
p(u, u)=\lim _{n \rightarrow \infty} p\left(u, x_{n}\right)=\lim _{n, m \rightarrow \infty} p\left(x_{n}, x_{m}\right)=0,
$$

implies

$$
\lim _{n \rightarrow \infty} d_{M}\left(u, x_{n}\right)=0 .
$$


Now, we have to prove that $u$ is a common fixed point of $T_{1}$ and $T_{2}$. For this, consider

$$
\begin{aligned}
& p\left(x_{2 n+1}, T_{1} u\right)=p\left(T_{1} x_{2 n}, T_{1} u\right) \\
& \leq \psi\left\{p\left(x_{2 n}, u\right), p\left(x_{2 n}, T_{1} x_{2 n}\right), p\left(u, T_{1} u\right),\right. \\
&\left.\frac{p\left(x_{2 n}, T_{1} u\right)+p\left(u, T_{1} x_{2 n}\right)}{2}\right\} \\
&=\psi\left\{p\left(x_{2 n}, x\right), p\left(x_{2 n}, x_{2 n+1}\right), p\left(u, T_{1} u\right),\right. \\
&\left.\frac{p\left(x_{2 n}, T_{1} u\right)+p\left(u, x_{2 n+1}\right)}{2}\right\} .
\end{aligned}
$$

Note that $\psi \in \Psi$, then using (1.10), Lemma 1.2 and taking the limit as $n \rightarrow \infty$, we get

$$
p\left(u, T_{1} u\right) \leq \psi\left(0,0, p\left(u, T_{1} u\right), \frac{p\left(u, T_{1} u\right)}{2}\right) .
$$

Since $\psi$ satisfies the condition $(r 2)$, then $p\left(u, T_{1} u\right) \leq h .0=0$. This shows that $u=T_{1} u$ for all $u \in X$. Similarly, we can show that $u=T_{2} u$. Thus, $u$ is a common fixed point of $T_{1}$ and $T_{2}$.

Now, to show that the common fixed point of $T_{1}$ and $T_{2}$ is unique. For this, let $u^{\prime}$ be another common fixed point of $T_{1}$ and $T_{2}$, that is, $T_{1} u^{\prime}=T_{2} u^{\prime}=u^{\prime}$ with $u^{\prime} \neq u$. Then we have to show that $u=u^{\prime}$. It follows from equation (1.7) and (1.10) that

$$
\begin{aligned}
p\left(u, u^{\prime}\right) & =p\left(T_{1} u, T_{2} u^{\prime}\right) \\
& \leq \psi\left\{p\left(u, u^{\prime}\right), p\left(u, T_{1} u\right), p\left(u^{\prime}, T_{2} u^{\prime}\right),\right. \\
\left.\frac{p\left(u, T_{2} u^{\prime}\right)+p\left(u^{\prime}, T_{1} u\right)}{2}\right\} & \psi \psi \\
& =\psi\left\{p\left(u, u^{\prime}\right), p(u, u), p\left(u^{\prime}, u^{\prime}\right),\right. \\
& \psi \psi \\
& =\left\{p\left(u, u^{\prime}\right)+p\left(u^{\prime}, u\right), 0,0, p\left(u, u^{\prime}\right)\right\} .
\end{aligned}
$$

Since $\psi$ satisfies the condition $(r 3)$, then we get

$$
\begin{aligned}
p\left(u, u^{\prime}\right) & \leq h p\left(u, u^{\prime}\right) \\
& \Rightarrow p\left(u, u^{\prime}\right)=0, \text { since } 0<h<1
\end{aligned}
$$

Thus, we get $u=u^{\prime}$. This shows that $u$ is the unique common fixed point of $T_{1}$ and $T_{2}$. This completes the proof. 
Theorem 1.3. Let $T_{1}$ and $T_{2}$ be two continuous self-maps on a complete partial metric space $(X, p)$ and

$$
\begin{aligned}
p\left(T_{1}^{m} x, T_{2}^{n} y\right) \leq \psi\left\{p(x, y), p\left(x, T_{1}^{m} x\right), p\left(y, T_{2}^{n} y\right),\right. & \left.\frac{p\left(x, T_{2}^{n} y\right)+p\left(y, T_{1}^{m} x\right)}{2}\right\}
\end{aligned}
$$

for all $x, y \in X$, where $m$ and $n$ are some integers and some $\psi \in \Psi$. Then $T_{1}$ and $T_{2}$ have a unique common fixed point in $X$.

Proof. Since $T_{1}^{m}$ and $T_{2}^{n}$ satisfy the conditions of Theorem 1.2. So $T_{1}^{m}$ and $T_{2}^{n}$ have a unique common fixed point. Let $z$ be the common fixed point. Then, we have

$$
\begin{aligned}
T_{1}^{m} z=z & \Rightarrow T_{1}\left(T_{1}^{m} z\right)=T_{1} z \\
& \Rightarrow T_{1}^{m}\left(T_{1} z\right)=T_{1} z .
\end{aligned}
$$

If $T_{1} z=z_{0}$, then $T_{1}^{m} z_{0}=z_{0}$. So, $T_{1} z$ is a fixed point of $T_{1}^{m}$. Similarly, $T_{2}\left(T_{2}^{n} z\right)=$ $T_{2} z$. Now, using equation (1.12) and Lemma 1.1, we obtain

$$
\begin{aligned}
p\left(z, T_{1} z\right) & =p\left(T_{1}^{m} z, T_{1}^{m}\left(T_{1} z\right)\right) \\
\leq & \psi\left\{p\left(z, T_{1} z\right), p\left(z, T_{1}^{m} z\right), p\left(T_{1} z, T_{1}^{m}\left(T_{1} z\right)\right)\right. \\
\left.\frac{p\left(z, T_{1}^{m}\left(T_{1} z\right)\right)+p\left(T_{1} z, T_{1}^{m} z\right)}{2}\right\} & \\
& =\psi\left\{p\left(z, T_{1} z\right), p(z, z), p\left(T_{1} z, T_{1} z\right),\right. \\
& \left.\frac{p\left(z, T_{1} z\right)+p\left(T_{1} z, z\right)}{2}\right\} \\
& \psi \psi\left\{p\left(z, T_{1} z\right), 0,0, \frac{p\left(z, T_{1} z\right)+p\left(z, T_{1} z\right)}{2}\right\} \\
& \psi \psi\left\{p\left(z, T_{1} z\right), 0,0, p\left(z, T_{1} z\right)\right\}
\end{aligned}
$$

Since $\psi$ satisfies the condition $(r 3)$, then we get

$$
\begin{aligned}
p\left(z, T_{1} z\right) & \leq h p\left(z, T_{1} z\right) \\
& \Rightarrow p\left(z, T_{1} z\right)=0, \text { since } 0<h<1 .
\end{aligned}
$$

Thus, we have $z=T_{1} z$ for all $z \in X$. Similarly, we can show that $z=T_{2} z$. This shows that $z$ is a common fixed point of $T_{1}$ and $T_{2}$. For the uniqueness of $z$, let $z^{\prime} \neq z$ be another common fixed point of $T_{1}$ and $T_{2}$. Then clearly $z^{\prime}$ is also a common fixed point of $T_{1}^{m}$ and $T_{2}^{n}$ which implies $z^{\prime}=z$. Hence $T_{1}$ and $T_{2}$ have a unique common fixed point. This completes the proof.

Theorem 1.4. Let $\left\{F_{\alpha}\right\}$ be a family of continuous self mappings on a complete partial metric space $(X, p)$ satisfying

$$
\begin{aligned}
p\left(F_{\alpha} x, F_{\beta} y\right) \leq \psi\left\{p(x, y), p\left(x, F_{\alpha} x\right), p\left(y, F_{\beta} y\right),\right. & \left.\frac{p\left(x, F_{\beta} y\right)+p\left(y, F_{\alpha} x\right)}{2}\right)
\end{aligned}
$$


for $\alpha, \beta \in \Psi$ with $\alpha \neq \beta$ and $x, y \in X$. Then there exists a unique $u \in X$ satisfying $F_{\alpha} u=u$ for all $\alpha \in \Psi$.

Proof. For $x_{0} \in X$, we define a sequence as follows:

$$
x_{2 n+1}=F_{\alpha} x_{2 n}, x_{2 n+2}=F_{\beta} x_{2 n+1}, n=0,1,2, \ldots
$$

It follows from (1.13), (p4) and Lemma 1.1 that

$$
\begin{aligned}
& p\left(x_{2 n+1}, x_{2 n}\right)=p\left(F_{\alpha} x_{2 n}, F_{\beta} x_{2 n-1}\right) \\
& \leq \psi\left\{p\left(x_{2 n}, x_{2 n-1}\right), p\left(x_{2 n}, F_{\alpha} x_{2 n}\right), p\left(x_{2 n-1}, F_{\beta} x_{2 n-1}\right)\right. \text {, } \\
& \left.\frac{p\left(x_{2 n}, F_{\beta} x_{2 n-1}\right)+p\left(x_{2 n-1}, F_{\alpha} x_{2 n}\right)}{2}\right\} \\
& =\psi\left\{p\left(x_{2 n}, x_{2 n-1}\right), p\left(x_{2 n}, x_{2 n+1}\right), p\left(x_{2 n-1}, x_{2 n}\right)\right. \text {, } \\
& \left.\frac{p\left(x_{2 n}, x_{2 n}\right)+p\left(x_{2 n-1}, x_{2 n+1}\right)}{2}\right\} \\
& \leq \psi\left\{p\left(x_{2 n}, x_{2 n-1}\right), p\left(x_{2 n}, x_{2 n+1}\right), p\left(x_{2 n-1}, x_{2 n}\right),\right. \\
& \left.\frac{p\left(x_{2 n-1}, x_{2 n}\right)+p\left(x_{2 n}, x_{2 n+1}\right)-p\left(x_{2 n}, x_{2 n}\right)}{2}\right\} \\
& \leq \psi\left\{p\left(x_{2 n}, x_{2 n-1}\right), p\left(x_{2 n}, x_{2 n+1}\right), p\left(x_{2 n-1}, x_{2 n}\right),\right. \\
& \left.\frac{p\left(x_{2 n-1}, x_{2 n}\right)+p\left(x_{2 n}, x_{2 n+1}\right)}{2}\right\} \text {. }
\end{aligned}
$$

Since $\psi$ satisfies the condition $(r 1)$, there exists $h \in(0,1)$ such that

$$
p\left(x_{2 n+1}, x_{2 n}\right) \leq h p\left(x_{2 n}, x_{2 n-1}\right) \leq h^{2 n} p\left(x_{1}, x_{0}\right) .
$$

Now, we show that $\left\{x_{n}\right\}$ is a Cauchy sequence in $X$. Let $m, n>0$ with $m>n$, then by using $(p 4)$ and equation (1.15), we have

$$
\begin{aligned}
p\left(x_{n}, x_{m}\right) \leq & p\left(x_{n}, x_{n+1}\right)+p\left(x_{n+1}, x_{n+2}\right)+\cdots+p\left(x_{n+m-1}, x_{m}\right) \\
& -p\left(x_{n+1}, x_{n+1}\right)-p\left(x_{n+2}, x_{n+2}\right)-\cdots-p\left(x_{n+m-1}, x_{n+m-1}\right) \\
\leq & h^{n} p\left(x_{0}, x_{1}\right)+h^{n+1} p\left(x_{0}, x_{1}\right)+\cdots+h^{n+m-1} p\left(x_{0}, x_{1}\right) \\
= & h^{n}\left[p\left(x_{0}, x_{1}\right)+h p\left(x_{0}, x_{1}\right)+\cdots+h^{m-1} p\left(x_{0}, x_{1}\right)\right] \\
= & h^{n}\left[1+h+\cdots+h^{m-1}\right] p\left(x_{0}, x_{1}\right) \\
\leq & h^{n}\left(\frac{1-h^{m-1}}{1-h}\right) p\left(x_{0}, x_{1}\right) .
\end{aligned}
$$

Taking $n, m \rightarrow \infty$ in the above inequality, we get $p\left(x_{n}, x_{m}\right) \rightarrow 0$ since $0<h<1$, hence $\left\{x_{n}\right\}$ is a Cauchy sequence in $X$. Thus, by Lemma 1.1 this sequence will also Cauchy in $\left(X, d_{M}\right)$. In addition, since $(X, p)$ is complete, $\left(X, d_{M}\right)$ is also complete. Thus there exists $v \in X$ such that $x_{n} \rightarrow v$ as $n \rightarrow \infty$. Moreover by Lemma 1.1,

$$
p(v, v)=\lim _{n \rightarrow \infty} p\left(v, x_{n}\right)=\lim _{n, m \rightarrow \infty} p\left(x_{n}, x_{m}\right)=0,
$$


implies

$$
\lim _{n \rightarrow \infty} d_{M}\left(v, x_{n}\right)=0 .
$$

By the continuity of $F_{\alpha}$ and $F_{\beta}$, it is clear that $F_{\alpha} v=F_{\beta} v=v$. Therefore $v$ is a common fixed point of $F_{\alpha}$ for all $\alpha \in \Psi$.

In order to prove the uniqueness, let us take another common fixed point $v^{\prime}$ of $F_{\alpha}$ and $F_{\beta}$ where $v \neq v^{\prime}$. Then from equation (1.13) and (1.16), we obtain

$$
\begin{aligned}
p\left(v, v^{\prime}\right) & =p\left(F_{\alpha} v, F_{\beta} v^{\prime}\right) \\
& \leq \psi\left\{p\left(v, v^{\prime}\right), p\left(v, F_{\alpha} v\right), p\left(v^{\prime}, F_{\beta} v^{\prime}\right),\right. \\
\left.\frac{p\left(v, F_{\beta} v^{\prime}\right)+p\left(v^{\prime}, F_{\alpha} v\right)}{2}\right\} & \\
& =\psi\left\{p\left(v, v^{\prime}\right), p(v, v), p\left(v^{\prime}, v^{\prime}\right),\right. \\
\left.\frac{p\left(v, v^{\prime}\right)+p\left(v^{\prime}, v\right)}{2}\right\} & \psi \psi \\
& =\left\{p\left(v, v^{\prime}\right), 0,0, p\left(v, v^{\prime}\right)\right\} .
\end{aligned}
$$

Since $\psi$ satisfies the condition $(r 3)$, then we get

$$
\begin{aligned}
p\left(v, v^{\prime}\right) & \leq h p\left(v, v^{\prime}\right) \\
& \Rightarrow p\left(v, v^{\prime}\right)=0, \text { since } 0<h<1 .
\end{aligned}
$$

Thus, we get $v=v^{\prime}$ for all $v \in X$. This shows that $v$ is a unique common fixed point of $F_{\alpha}$ for all $\alpha \in \Psi$. This completes the proof.

Next, we give analogues of fixed point theorems in metric spaces for partial metric spaces by combining Theorem 1.1 with $\psi \in \Psi$ and $\psi$ satisfies conditions $(r 1),(r 2)$ and $(r 3)$. The following corollary is an analogue of Banach's contraction principle.

Corollary 1.1. Let $(X, p)$ be a complete partial metric space. Suppose that the mapping $T: X \rightarrow X$ satisfies the following condition:

$$
p(T x, T y) \leq a p(x, y)
$$

for all $x, y \in X$, where $a \in[0,1)$ is a constant. Then $T$ has a unique fixed point in $X$. Moreover, $T$ is continuous at the fixed point.

Proof. The assertion follows using Theorem 1.1 with $\psi\left(u_{1}, u_{2}, u_{3}, u_{4}\right)=a u_{1}$ for some $a \in[0,1)$ and all $u_{1}, u_{2}, u_{3}, u_{4} \in \mathbb{R}_{+}$.

The following corollary is an analogue of R. Kannan's result [7]. 
Corollary 1.2. Let $(X, p)$ be a complete partial metric space. Suppose that the mapping $T: X \rightarrow X$ satisfies the following condition:

$$
p(T x, T y) \leq b[p(x, T x)+p(y, T y)]
$$

for all $x, y \in X$, where $b \in\left[0, \frac{1}{2}\right)$ is a constant. Then $T$ has a unique fixed point in $X$. Moreover, $T$ is continuous at the fixed point.

Proof. The assertion follows using Theorem 1.1 with $\psi\left(u_{1}, u_{2}, u_{3}, u_{4}\right)=b\left(u_{2}+u_{3}\right)$ for some $b \in\left[0, \frac{1}{2}\right)$ and all $u_{1}, u_{2}, u_{3}, u_{4} \in \mathbb{R}_{+}$. Indeed, $\psi$ is continuous. First, we have $\psi\left(x, x, y, \frac{x+y}{2}\right)=b(x+y)$. So, if $y \leq \psi\left(x, x, y, \frac{x+y}{2}\right)$, then $y \leq\left(\frac{b}{1-b}\right) x$ with $\left(\frac{b}{1-b}\right)<1$. Thus, $T$ satisfies the condition $(r 1)$.

Next, if $y \leq \psi\left(0,0, y, \frac{y}{2}\right)=b(0+y)=b y$, then $y=0$, since $b<\frac{1}{2}<1$. Thus, $T$ satisfies the condition $(r 2)$. $(r 3)$.

Finally, if $y \leq \psi(y, 0,0, y)=b .0=0$, then $y=0$. Thus, $T$ satisfies the condition

The following corollary is an analogue of S. K. Chatterjae's result [6].

Corollary 1.3. Let $(X, p)$ be a complete partial metric space. Suppose that the mapping $T: X \rightarrow X$ satisfies the following condition:

$$
p(T x, T y) \leq c[p(x, T y)+p(y, T x)]
$$

for all $x, y \in X$, where $c \in\left[0, \frac{1}{2}\right)$ is a constant. Then $T$ has a unique fixed point in $X$. Moreover, $T$ is continuous at the fixed point.

Proof. The assertion follows using Theorem 1.1 with $\psi\left(u_{1}, u_{2}, u_{3}, u_{4}\right)=c u_{4}$ for some $c \in[0,1)$ and all $u_{1}, u_{2}, u_{3}, u_{4} \in \mathbb{R}_{+}$. Indeed, $\psi$ is continuous. First, we have $\psi\left(x, x, y, \frac{x+y}{2}\right)=c\left(\frac{x+y}{2}\right)$. So, if $y \leq \psi\left(x, x, y, \frac{x+y}{2}\right)$, then $y \leq\left(\frac{c}{2-c}\right) x$ with $\left(\frac{c}{2-c}\right)<1$. Thus, $T$ satisfies the condition $(r 1)$. $(r 2)$.

Next, if $y \leq \psi\left(0,0, y, \frac{y}{2}\right)$, then $y=0$ since $c<1$. Thus, $T$ satisfies the condition

Finally, if $y \leq \psi(y, 0,0, y)=c y$, then $y=0$ since $c<1$. Thus, $T$ satisfies the condition $(r 3)$.

The following corollary is an analogue of S. Reich's result [16].

Corollary 1.4. Let $(X, p)$ be a complete partial metric space. Suppose that the mapping $T: X \rightarrow X$ satisfies the following condition:

$$
p(T x, T y) \leq L_{1} p(x, y)+L_{2} p(x, T x)+L_{3} p(y, T y)
$$

for all $x, y \in X$, where $L_{1}, L_{2}, L_{3} \geq 0$ are constants with $L_{1}+L_{2}+L_{3}<1$. Then $T$ has a unique fixed point in $X$. Moreover, if $L_{3}<\frac{1}{2}$, then $T$ is continuous at the fixed point. 
Proof. The assertion follows using Theorem 1.1 with $\psi\left(u_{1}, u_{2}, u_{3}, u_{4}\right)=L_{1} u_{1}+$ $L_{2} u_{2}+L_{3} u_{3}$ for some $L_{1}, L_{2}, L_{3} \geq 0$ are constants with $L_{1}+L_{2}+L_{3}<1$ and all $u_{1}, u_{2}, u_{3}, u_{4} \in \mathbb{R}_{+}$. Indeed, $\psi$ is continuous. First, we have $\psi\left(x, x, y, \frac{x+y}{2}\right)=$ $L_{1} x+L_{2} x+L_{3} y$. So, if $y \leq \psi\left(x, x, y, \frac{x+y}{2}\right)$, then $y \leq\left(\frac{L_{1}+L_{2}}{1-L_{3}}\right) x$ with $\left(\frac{L_{1}+L_{2}}{1-L_{3}}\right)<1$. Thus, $T$ satisfies the condition $(r 1)$.

Next, if $y \leq \psi\left(0,0, y, \frac{y}{2}\right)=L_{1} .0+L_{2} .0+L_{3} . y=L_{3} y$, then $y=0$ since $L_{3}<1$. Thus, $T$ satisfies the condition $(r 2)$.

Finally, if $y \leq \psi(y, 0,0, y)=L_{1} . y+L_{2} .0+L_{3} .0=L_{1} y$, then $y=0$ since $L_{1}<1$. Thus, $T$ satisfies the condition $(r 3)$.

Example 1.3. Let $X=[0,1]$. Define $p: X \times X \rightarrow \mathbb{R}^{+}$as $p(x, y)=\max \{x, y\}$ with $T: X \rightarrow X$ by $T(x)=\frac{x}{3}$. Clearly $(X, p)$ is a partial metric space. Now, let $x \leq y$. Then choose $x=\frac{1}{2}$ and $y=1$, we have $p(T x, T y)=\frac{y}{3}, p(x, y)=y, p(x, T x)=x, p(y, T y)=y$, $p(x, T y)=x, p(y, T x)=y$.

(i) Now, we consider

$$
p(T x, T y)=\frac{y}{3} \leq a y,
$$

or $a \geq \frac{1}{3}$. If we take $0 \leq a<1$, then $T$ satisfies all the conditions of Corollary 1.1. Hence, applying Corollary 1.1, $T$ has a unique fixed point. Here it is seen that $0 \in X$ is the unique fixed point of $T$.

(ii) Now, we consider

$$
p(T x, T y)=\frac{y}{3} \leq b(x+y),
$$

putting $x=\frac{1}{2}$ and $y=1$ in the above inequality, we get

$$
\frac{1}{3} \leq \frac{3}{2} b
$$

or $b \geq \frac{2}{9}$. If we take $0 \leq b<\frac{1}{2}$, then $T$ satisfies all the conditions of Corollary 1.2. Hence, applying Corollary 1.2, $T$ has a unique fixed point and the unique fixed point $T$ is $0 \in X$.

(iii) Now, we consider

$$
p(T x, T y)=\frac{y}{3} \leq c(x+y)
$$

putting $x=\frac{1}{2}$ and $y=1$ in the above inequality, we get

$$
\frac{1}{3} \leq \frac{3}{2} c
$$

or $c \geq \frac{2}{9}$. If we take $0 \leq c<\frac{1}{2}$, then $T$ satisfies all the conditions of Corollary 1.3. Hence, applying Corollary 1.3, $T$ has a unique fixed point and it is $0 \in X$. 
(iv) Now, we consider

$$
p(T x, T y)=\frac{y}{3} \leq L_{1} y+L_{2} x+L_{3} y,
$$

putting $x=\frac{1}{2}$ and $y=1$ in the above inequality, we get

$$
\frac{1}{3} \leq L_{1}+\frac{1}{2} L_{2}+L_{3}
$$

If we take (1) $L_{1}=\frac{1}{3}, L_{2}=\frac{1}{2}$ and $L_{3}=0$ (2) $L_{1}=\frac{1}{2}, L_{2}=0$ and $L_{3}=\frac{1}{3}$ and (3) $L_{1}=0$, $L_{2}=\frac{1}{4}$ and $L_{3}=\frac{1}{5}$, then $T$ satisfies all the conditions of Corollary 1.4. Hence, applying Corollary $1.4, T$ has a unique fixed point and it is $0 \in X$.

Open Question: Can we extend the results for graphic contraction as defined in Younis et al. [22, 23, 24]?

\section{Conclusion}

In this paper, we have established some fixed point and common fixed point theorems using implicit relation in the framework of complete partial metric spaces, and also obtained the well-known Banach contraction principle, Kannan contraction, Chatterjae contraction and Reich contraction as corollaries to the result. The results extend, unify and generalize several results from the existing literature to the setting of a more general class of metric spaces and contraction conditions.

\section{Acknowledgement}

The author would like to convey his gratitude to the anonymous referees for their careful reading and valuable suggestions to improve the manuscript.

\section{R E F E R E N C E S}

1. T. ABDEljawAd, E. KARAPINAR and K. TAS: Existence and uniqueness of common fixed point partial metric spaces, Appl. Math. Lett. in press (doi:10.1016/j.aml.2011.05.014).

2. I. Altun, F. Sola and H. Simsek: Generalized contractions on partial metric spaces, Topology Appl. 157 (2010), 2778-2785.

3. I. Altun and A. ERduran: Fixed point theorems for monotone mappings on partial metric spaces, Fixed Point Theory Appl. 2011 (2011), Article ID 508730, 10 pages.

4. H. Aydi, M. AbBas and C. Vetro: Partial Hausdorff metric and Nadler's fixed point theorem on partial metric spaces, Topology and Its Appl. 159 (2012), No. 14, 3234-3242.

5. S. BANACH: Surles operation dans les ensembles abstraits et leur application aux equation integrals, Fund. Math. 3 (1922), 133-181.

6. S. K. Chatterjae: Fixed point theorems compactes, Rend. Acad. Bulgare Sci. 25 (1972), 727-730. 
7. R. KAnnan: Some results on fixed point theorems, Bull. Calcutta Math. Soc. 60 (1969), $71-78$.

8. E. KARAPINAR and U. YüKSEL: Some common fixed point theorems in partial metric space, J. Appl. Math. 2011, Article ID: 263621, 2011.

9. E. KARAPINAR and INCI M. ERHAN: Fixed point theorems for operators on partial metric spaces, Appl. Math. Lett. 24 (2011), 1894-1899.

10. E. KarAPinaR: Weak $\phi$-contraction on partial metric spaces, J. Comput. Anal. Appl. (in press).

11. H. P. A. KüNZI: Nonsymmetric distances and their associated topologies about the origins of basic ideas in the area of asymptotic topology, Handbook of the History Gen. Topology (eds. C.E. Aull and R. Lowen), Kluwer Acad. Publ., 3 (2001), 853-868.

12. S. G. Matthews: Partial metric topology, Research report 2012, Dept. Computer Science, University of Warwick, 1992.

13. S. G. Matthews: Partial metric topology, Proceedings of the 8th summer conference on topology and its applications, Annals of the New York Academy of Sciences, 728 (1994), 183-197.

14. H. K. Nashine, Z. Kadelburg, S. RadenoviC and J. K. Kim: Fixed point theorems under Hardy-Rogers contractive conditions on 0-complete ordered partial metric spaces, Fixed Point Theory Appl. 2012 (2012), 1-15.

15. S. Oltra and O. VAlero: Banach's fixed point theorem for partial metric spaces, Rend. Istit. Mat. Univ. Trieste 36 (2004), 17-26.

16. S. REICH: Some remarks concerning contraction mappings, Canad. Math. Bull. 14 (1971), 121-124.

17. M. Schellekens: A characterization of partial metrizibility: domains are quantifiable, Theoritical Computer Science, 305(1-3) (2003), 409-432.

18. O. Vetro: On Banach fixed point theorems for partial metric spaces, Appl. Gen. Topology 6 (2005), No. 12, 229-240.

19. P. Waszkiewicz: Partial metrizibility of continuous posets, Mathematical Structures in Computer Science 16(2) (2006), 359-372.

20. M. Younis, D. Singh, S. RAdenović and M. Imdad: Convergence theorems via generalized contractions and its applications, Filomat 34(3) (2020).

21. M. Younis, D. Singh, D. Gopal, A. Goyal and M. S. Rathore: On applications of generalized F-contraction to differential equations, Nonlinear Funct. Anal. Appl. 24(1) (2019), 155-177.

22. M. Younis, D. Singh and A. Petrusel: Applications of graph Kannan mappings to the damped spring-mass system and deformation of an elastic beam, Discrete Dynamics in Nature and Society, vol. 2019, Article ID 1315387, 9 pages, 2019. (doi.org/10.1155/2019/1315387).

23. M. Younis, D. Singh and A. Goyal: A novel approach of graphical rectangular bmetric spaces with an application to the vibrations of a vertical heavy hanging cable, J. Fixed Point Theory Appl. 21(1):33, (2019).

24. M. Younis, D. Singh, M. Asadi and V. Joshi: Results on contractions of Reich type in graphical b-metric spaces with applications, Filomat 33(17) (2019), 5723-5735. 
Gurucharan Singh Saluja

Department of Mathematics

Govt. K.P.G. College Jagdalpur

Jagdalpur - 494001 (Chhattisgarh), India.

saluja1963@gmail.com 